\title{
Evaluation of Nutrition Surveys in Flood-affected Areas of Pakistan: Seeing the Unseen!
}

\author{
S.M. Moazzem Hossain, Mah Talat, Erin Boyd, \\ Shamim Rafique Chowdhury, Sajid Bashir Soofi, Imtiaz Hussain, \\ Imran Ahmed, Rehana Abdus Salam and Zulfiqar A. Bhutta***
}

\begin{abstract}
In 2010 Pakistan experienced the worst floods recorded in its history; millions of people were affected and thousands lost their lives. Nutrition assessment surveys led by UNICEF were conducted in flood-affected areas of Punjab and Sindh provinces to assess the nutrition status of children between 6-59 months while Aga Khan University (AKU) undertook a parallel assessment including micronutrient status in their project areas within Balochistan, Sindh and Punjab. Standardised Monitoring and Assessment of Relief and Transition (SMART) methodology was used. 881 children from Sindh, 1,143 from Punjab and 817 from AKU project areas were measured for anthropometry and their households were interviewed. The findings indicated that while immediate life-saving interventions were essential, there was also an urgent need to address chronic malnutrition. Through high-level dissemination of the survey results, treatment and prevention of malnutrition has become a priority for the provincial and federal government in Pakistan and for donors.
\end{abstract}

\section{Background}

The Islamic Republic of Pakistan is located in South Asia, in the north-western part of the subcontinent and covers an area of 796,096 sq km. Pakistan is a federal republic with four autonomous provinces: Balochistan, Sindh, Punjab, and Khyber Pakhtunkhwa (KPk) in addition to the Federally Administered Tribal Areas (FATA), Gilgit-Baltistan and the Islamabad Capital Territory. There is also the disputed area of Kashmir, divided by a Line of Control between India and Pakistan for many decades. Provinces are divided into districts, teshils/talukas (administrative divisions), union councils and lastly towns/villages/dehs (cluster of villages).

In terms of seasonality, Pakistan can be divided into four yearly patterns:

- The cold season (December to March);

- The hot season (April to June), which is usually dry;

- The monsoon season (July to September), which is responsible for yearly flooding that also increases the risk of landslides, especially in northern regions; and

- The post-monsoon season (October and November).

The geography varies from high mountains to temperate plains, to large desert areas and semitropical coastal areas. Climate change, chiefly warming, is having different effects on the varied terrain and seasons with extremes of drought and flood becoming more common. Over the course of the monsoon season in July and August 2010, Pakistan experienced some of the worst floods recorded in recent history. They began with the heavy monsoon rains in the Khyber Pakhtunkhwa, Punjab, Sindh, Gilgit-Baltistan, Balochistan and Pakistan-Administered Kashmir regions of Pakistan. Sindh and southern Punjab were affected later than the other areas with lower fatalities, but a greater proportion of the population was affected. Significant numbers of the population were affected by flood response, that is, the breaching of dykes to save major cities. The floods affected around 20 million people (UNOCHA 2010) and almost half of them 
were children, or more than one-tenth of Pakistan's child population. About 1,700 men, women and children lost their lives, and around 1.8 million homes were damaged or destroyed. Flooding also affected about 160,000sq km of land (almost one-fifth of the country's area), including 2.4 million hectares of cultivable land where crops such as rice, maize, sugarcane, fruit orchard and vegetables were destroyed or damaged (UNOCHA 2010). It was estimated that about 1.2 million livestock, including cattle used for ploughing, were drowned in the floods, leading to a massive humanitarian crisis in Pakistan. Seeds and grains intended to be used for wheat planting in September/October were lost, which meant that farmers were not able to harvest wheat again before spring 2011.

Sindh was the province worst affected by the floods, followed by Punjab, Khyber Pakhtunkhwa, and Balochistan. There had not been a largescale nutrition survey conducted in a decade in Pakistan and little representative local information was available. Based on the context, the humanitarian response community decided to conduct Flood-Affected Nutrition Surveys (FANS) in the four provinces of Pakistan in order to assess how the floods had affected the nutrition status of children and identify its correlates and main aggravating factors.

\section{Objectives of the surveys}

This process started with Sindh flood-affected areas, followed by Punjab, then KPk and Balochistan where the surveys followed a similar design, that is, cross-sectional surveys supported by UNICEF and approved by the Nutrition Cluster. The Aga Khan University (AKU) implemented a concerted response plan in ten severely affected districts of Balochistan, Sindh and Punjab with support from its staff and additional funding from USAID. The baseline survey in AKU focus districts was also designed to provide baseline information for the potential evaluation of programme interventions. Given the proximity of timing and congruence of the affected population, these surveys are discussed together in this article.

The UNICEF-supported surveys in Sindh and Punjab were designed to provide updated information on the nutritional situation of children between 6-59 months in flood-affected areas and to recommend immediate, medium and long-term interventions to save lives and support livelihoods.

\section{Methods}

Two different study designs and methods were followed in the surveys conducted by UNICEF (in Sindh and Punjab) and by AKU (in their project areas) around October-December 2010, which are described separately.

\section{a UNICEF-supported FANS (Sindh and Punjab)}

In both provinces, the surveys used the SMART approach for sampling, anthropometry and analysis; and the World Health Organization (WHO) growth standards were used as a reference point to classify malnourished children. The surveys were undertaken using a cluster sampling methodology. Both surveys were conducted by the Department of Health (DoH) in collaboration with UNICEF, ACF-Canada and the Center for Disease Control (CDG). In Punjab, the data collection was done by the Punjab Bureau of Statistics.

\section{Geographical location and timeline}

In Sindh, two surveys were conducted, one in northern Sindh (Ghotki, Jacobabad, Kashmore, Khairpur, Larkana, Shahdadkot, Shikarpur and Sukkur districts) and southern Sindh (Dadu, Hyderabad, Nawabshah, Jamshoro, Matiari, Noushero Feroz and Thatta districts). Both residents and internally displaced persons (IDPs) were included in the surveys. The survey data collection took place 29 October-4 November 2010 (DoH/UNICEF/ACF 2011).

In Punjab two surveys were also done, one in the severely flood-affected areas (D.G. Khan, Muzaffargarh, Rajanpur and Layyah districts) and the other one in the moderately floodaffected areas (Jhang, Bhakkar, Mianwali, Khushab and Rahim Yar Khan districts). Both surveys included only households as there were no IDP camps. The survey data collection took place 1 November-15 November 2010 (Rafique $e t$ al. 2011).

\section{Sample size and sampling}

In Sindh, a total of 35 clusters were selected for each of the surveys, making it 70 clusters for the whole of Sindh while 786 households were interviewed (397 in the north and 389 in the south) and 881 children between 6-59 months (467 in the north and 414 in the south) were measured for anthropometry. 
Household (HH): A household constitutes all those persons living together and eating/sharing their meals from the same kitchen. A household may consist of one or more persons who may or may not be related to each other.

Household status: Household information was collected about the status of the $\mathrm{HH}$ (resident, returnee or IDP), and the type of housing ( $k a c h a$ or pacca materials for floor, roof and walls). Also, food consumption was measured by food frequency at HH level for the last seven days. Questions were also asked about the drinking water source, latrine facility and soap use at HH level. Finally, there were questions about assets, possessions, distress sales and uptake of a loan or receiving financial assistance in order to understand the coping mechanism and current status of livelihoods. All questions at HH level followed the standard set of UNICEF's Multiple Indicator Cluster Surveys (MICS).

Anthropometric measurements: The children aged 6-59 months who were present in the household at the time of interview were included. Researchers tried to confirm the age from the evidence, i.e. from the Expanded Programme of Immunisation (EPI) card or household diary. If the age was still unknown, further investigation was done by using different age determining techniques such as event calendars, etc.

Height: Between $65-110 \mathrm{~cm}$. For children less than two years of age and measuring $65-86 \mathrm{~cm}$, length was measured with the child lying down, and for those $87-110 \mathrm{~cm}$ tall, by standing them on the measuring board provided. Height was measured to the nearest $0.1 \mathrm{~cm}$ and length to the nearest $0.2 \mathrm{~cm}$ (the new plastic machines do not have $0.1 \mathrm{~cm}$ calibration).

Weight of children was determined using the digital weighing machines, especially designed for the purpose, and was provided to the enumerators. Weight was taken to the nearest $100 \mathrm{~g}$ and mid-upper arm circumference (MUAC) to the nearest $0.1 \mathrm{~cm}$.

Oedema was diagnosed using the thumb pressure test on both feet simultaneously. Each case of reported oedema was re-checked by supervisors and independent monitors for confirmation.

Global Acute Malnutrition (GAM): Defined as a WFH $<-2$ z-score; Severe Acute Malnutrition $(\mathrm{SAM})$ as a WFH $<-3$ z-score and/or oedema. WFH was determined using the WHO standards.

Any illness within last two weeks: For illness, only diarrhoea, Acute Respiratory Infection (ARI) and fever were assessed for children 6-59 months for the two weeks prior to survey date. Diarrhoea was defined as three or more loose or watery stools per day, whereas ARI was described as difficulty in breathing with fever.

Feeding practices: Children aged 6-24 months were included for the Infant and Young Child Feeding (IYCF) indicators, and the question was asked as to whether the child is currently breastfed and, if yes, when this was initiated.

Wealth quintile: Asset rankings have been defined using the Principal Components Analysis (PCA) technique. This procedure first standardises the indicator variables (calculating z-scores); then the factor coefficient scores (factor loadings) are calculated; and finally, for each household, the indicator values are multiplied by the loadings and summed to produce the household's index value. In this process, only the first of the factors produced is used to represent the wealth index. The resulting sum is itself a standardised score with a mean of zero and a standard deviation of one. And the final score is divided into five equal parts to produce the wealth quintile. 
In Punjab, a total of 30 clusters were selected for each survey, making it 60 clusters for the whole of Punjab and approximately 1,200 households (600 in each survey area) were approached and a total of 1,143 children between 6-59 months (612 from severely affected and 531 from moderately affected areas) were measured for their anthropometry.

Sample sizes required were drawn by the CDC using an ENA SMART calculator. Training was conducted by the Bureau of Statistics (BOS) and UNICEF with technical support from CDC and ACF-Canada.

\section{Major variables}

The main indicators measured were a child's acute and chronic malnutrition level, vitamin A supplementation, measles vaccination, child morbidity, food consumption and access to water and sanitation at household level for Sindh, while in Punjab additional information on Infant and Young Child Feeding (IYCF) practice, food consumption, sources of food, income variables and coping mechanisms were included.

\section{Survey teams, training and supervision}

In each location, five teams collected data. Each team comprised one team leader and two groups consisting of one male and two female members. Independent monitors were available to support the teams by doing field visits. Five days of training were provided for the enumerators and supervisors.

\section{Data management}

Data editing, cleaning, entry and analysis was done by Eycon (Pvt) Ltd, engaged by UNICEF under the supervision of the Punjab Bureau of Statistics using ENA SMART software for individual anthropometry data and SPSSPC + for household information. A double data entry option was used for quality control. Plausibility check outputs were given every 2-3 days to the team leaders for correcting mistakes in subsequent days. Data cleaning were based on exclusion of SMART flags: WHZ: -3 to +3 ; HAZ: -3 to +3 ; WAZ: -3 to +3 .

\section{b AKU nutrition survey (project areas of Sindh, Punjab and Balochistan)}

AKU conducted a cross-sectional survey in ten flood-affected districts (Thatta, Dadu, Naushero Feroze, Sukkur, Shikarpur, Larkana (Sindh), Rahimyar Khan, Muzzafarghar, Rajan Pur (southern Punjab) and Jaffarabad (Balochistan). The survey was undertaken in November 2010. Approval was obtained from the ethics review committee of AKU to conduct the survey with formal community consent. The population for the survey was defined as the catchment population residing in the catchment area of the medical camps of AKU that were established for humanitarian support and preventive health interventions. The total catchment population was divided into four segments on the basis of population. A total sample size of 1,000 (250/segment) was estimated on the basis of stipulated anaemia prevalence among children under five; the sample size was equally distributed across all districts.

Three teams with two nurses, two data collectors and one team leader per team were hired and supervised by a dedicated senior research supervisor from AKU. A five-day intensive training was conducted on survey objectives, methodology and standard operating procedures for anthropometric measurements and blood sampling and processing techniques. A structured instrument was developed which was pre-tested in the field visit during the training.

A household was defined as a group of people who routinely ate out of same pot and lived at the same physical location. Households residing in the same geographical area for the next six months were considered for assessment. The target group was women of reproductive age (15-49 years) and children under five years of age. Equivalent campsites from each district were selected randomly based on probability proportional to size available through a quick count of households in each area. Within each campsite, households were selected using systematic random sampling.

The data was collected on paper forms that were reviewed by the team leaders for completeness and errors while the anthropometric measurements were validated using ENA SMART software by the field supervisor on a daily basis. The data was sent to the data management unit of AKU where data was double entered and was analysed using SPSS 16.

\section{Combined analysis}

For the purpose of this article, all datasets from all three surveys have been pooled together and to 


\begin{tabular}{|c|c|c|c|c|c|}
\hline & \multicolumn{2}{|c|}{ Sindh FANS UNICEF } & \multicolumn{2}{|c|}{ Punjab FANS UNICEF } & \multirow[b]{2}{*}{ AKU surveys } \\
\hline & North Sindh & South Sindh & Severely affected & $\begin{array}{l}\text { Moderately } \\
\text { affected }\end{array}$ & \\
\hline \multicolumn{6}{|l|}{ Geographical area } \\
\hline No of Clusters & 34 & 34 & 30 & 30 & 40 \\
\hline $\mathrm{HH}$ interviewed & 397 & 389 & 600 & 600 & 945 \\
\hline Children measured & 467 & 414 & 612 & 531 & 817 \\
\hline \multicolumn{6}{|c|}{ Age group of children 6-59 months } \\
\hline 6-11m & $43(9.2)$ & $42(10.2)$ & $56(9.2)$ & $40(7.5)$ & $100(12.2)$ \\
\hline $12-23 m$ & $102(21.9)$ & $74(18)$ & $135(22.2)$ & $128(24.1)$ & $215(26.3)$ \\
\hline $24-35 m$ & $123(26.5)$ & $107(26)$ & $127(20.9)$ & $128(24.1)$ & $190(23.3)$ \\
\hline $36-47 m$ & $102(21.9)$ & $103(25.1)$ & $156(25.7)$ & $133(25)$ & $183(22.4)$ \\
\hline $48-59 m$ & $95(20.4)$ & $85(20.7)$ & $134(22)$ & $102(19.2)$ & $129(15.8)$ \\
\hline N & 465 & 411 & 608 & 531 & 817 \\
\hline \multicolumn{6}{|l|}{ Type of housing } \\
\hline Mud/mud brick & $150(38.3)$ & $210(54.5)$ & 270 (53.7) & $401(70.5)$ & $191(20.2)$ \\
\hline Stone/concrete/brick & $118(30.1)$ & $96(24.9)$ & $108(21.5)$ & $159(27.9)$ & - \\
\hline Thatch & $81(20.7)$ & $58(15.1)$ & $15(3)$ & $4(0.7)$ & $363(38.4)$ \\
\hline Plastic sheet/tarpaulin/tent & $43(11)$ & $12(3.1)$ & $62(12.3)$ & $2(0.4)$ & - \\
\hline Others & $\mathrm{O}(0)$ & $9(2.3)$ & $48(9.5)$ & $3(0.5)$ & $250(26.5)$ \\
\hline Not reported & - & - & - & - & $141(14.9)$ \\
\hline N & 392 & 385 & 503 & 569 & 945 \\
\hline \multicolumn{6}{|l|}{ Kind of toilet facility } \\
\hline Flush/pour flush toilet & 115 (29.6) & $141(36.7)$ & $215(36.3)$ & $247(41.5)$ & $414(43.8)$ \\
\hline Pit latrine & $84(21.6)$ & 39 (10.2) & $21(3.5)$ & $12(2)$ & $189(20.0)$ \\
\hline No facilities, bush or field & $180(46.3)$ & $191(49.7)$ & $352(59.5)$ & $335(56.3)$ & 330 (34.9) \\
\hline Others & $10(2.6)$ & $13(3.4)$ & $4(0.7)$ & $1(0.2)$ & $12(1.3)$ \\
\hline N & 389 & 384 & 592 & 595 & 945 \\
\hline \multicolumn{6}{|c|}{ Soap availability at household for handwashing (observed) } \\
\hline Yes & $256(66.5)$ & $267(71.8)$ & $396(67)$ & $477(80)$ & $808(85.5)$ \\
\hline No & $129(33.5)$ & $105(28.2)$ & $195(33)$ & $119(20)$ & $137(14.5)$ \\
\hline N & 385 & 372 & 591 & 596 & 945 \\
\hline \multicolumn{6}{|c|}{ Main source of drinking water for the household } \\
\hline Piped water & $14(3.6)$ & $29(7.6)$ & $123(20.8)$ & $67(11.2)$ & $118(12.5)$ \\
\hline Hand pump/motor pump & $345(88.5)$ & $302(78.6)$ & $450(76)$ & $506(84.9)$ & $788(83.4)$ \\
\hline Supplied by NGO/Govt. & $10(2.6)$ & $28(7.3)$ & $0(0)$ & $1(0.2)$ & $17(1.8)$ \\
\hline Others & $21(5.4)$ & $25(6.5)$ & $19(3.2)$ & $22(3.7)$ & $22(2.3)$ \\
\hline $\mathrm{N}$ & 390 & 384 & 592 & 596 & 945 \\
\hline \multicolumn{6}{|l|}{ Quintile } \\
\hline Quintile I (lowest) & $149(37.5)$ & $188(48.3)$ & $95(15.8)$ & $59(9.8)$ & $192(20.3)$ \\
\hline Quintile II & $42(10.6)$ & $10(2.6)$ & $184(30.7)$ & $185(30.8)$ & $193(20.4)$ \\
\hline Quintile III & $83(20.9)$ & 75 (19.3) & $133(22.2)$ & $130(21.7)$ & $185(19.6)$ \\
\hline Quintile IV & 87 (21.9) & $60(15.4)$ & $69(11.5)$ & $99(16.5)$ & $191(20.2)$ \\
\hline Quintile V (highest) & $36(9.1)$ & $56(14.4)$ & $119(19.8)$ & $127(21.2)$ & $184(19.5)$ \\
\hline N & 397 & 389 & 600 & 600 & 945 \\
\hline \multicolumn{6}{|l|}{$\mathrm{N}=$ sample size. } \\
\hline
\end{tabular}


Table 2 Malnutrition situation in five different survey areas (along with confidence intervals - Cls)

\begin{tabular}{|c|c|c|c|c|c|}
\hline & \multicolumn{2}{|c|}{ Sindh FANS UNICEF } & \multicolumn{2}{|c|}{ Punjab FANS UNICEF } & \multirow[b]{2}{*}{ AKU surveys } \\
\hline & North Sindh & South Sindh & $\begin{array}{l}\text { Severely } \\
\text { affected }\end{array}$ & $\begin{array}{l}\text { Moderately } \\
\text { affected }\end{array}$ & \\
\hline $\begin{array}{l}\text { Global Acute } \\
\text { Malnutrition (GAM) }\end{array}$ & $\begin{array}{l}(98) 22.9 \% \\
(19.0-27.4 \mathrm{Cl})\end{array}$ & $\begin{array}{l}\text { (79) } 21.2 \% \\
(17.3-25.6 \mathrm{Cl})\end{array}$ & $\begin{array}{l}\text { (81) } 13.8 \% \\
(10.2-18.4 \mathrm{Cl})\end{array}$ & $\begin{array}{l}(70) 14.0 \% \\
(10.5-18.4 \mathrm{Cl})\end{array}$ & $\begin{array}{l}(103) 15.7 \% \\
(12.9-18.5 \mathrm{Cl})\end{array}$ \\
\hline Stunting & $\begin{array}{l}\text { (213) } 53.9 \% \\
(46.2-61.5 \mathrm{Cl})\end{array}$ & $\begin{array}{l}(185) 51.8 \% \\
(44.5-59.0 \mathrm{Cl})\end{array}$ & $\begin{array}{l}(224) 46.8 \% \\
(42.3-51.2 \mathrm{Cl})\end{array}$ & $\begin{array}{l}(288) 52.7 \% \\
(48.6-56.9 \mathrm{Cl})\end{array}$ & $\begin{array}{l}(340) 47.6 \% \\
(43.9-51.2 \mathrm{Cl})\end{array}$ \\
\hline Underweight & $\begin{array}{l}(196) 46.2 \% \\
(38.8-53.8 \mathrm{Cl})\end{array}$ & $\begin{array}{l}(179) 47.9 \% \\
(41.2-54.6 \mathrm{Cl})\end{array}$ & $\begin{array}{l}(187) 38.4 \% \\
(34.2-42.8 \mathrm{Cl})\end{array}$ & $\begin{array}{l}(229) 40.2 \% \\
(36.3-44.3 \mathrm{Cl})\end{array}$ & $\begin{array}{l}(413) 65.1 \% \\
(61.4-68.9 \mathrm{Cl})\end{array}$ \\
\hline
\end{tabular}

Source Authors' own.

be consistent and comparable, only those variables (type of housing, toilet facility, soap availability, source of drinking water, breastfeeding, morbidity and vitamin A supplementation) have been used that were common in all three surveys, and the sample population has been limited to $6-59$ months. No new analysis has been done for calculating z-scores but the same flag (SMART) has been applied on AKU data as well. Wealth quintiles have been calculated for Sindh and Punjab data using the definition used in AKU surveys. However, the results have been presented in three different columns for three different surveys since a total is not possible due to the different methodologies and time frame of the surveys. The concept and definition of the major variables are described in Box 1.

\section{Results}

\subsection{Socioeconomic status}

Information from 1,986 households (786 from Sindh, 1,200 from Punjab and 945 from AKU projects) was obtained and measurement of 2,819 children between 6-59 months (859 from Sindh, 1,143 from Punjab and 817 from AKU projects) have been analysed. Children were found to be equally distributed among different age groups (class interval of 12 months except the youngest group of 6-11 months). It was found that around 5 per cent of the population lived in IDP camps in Sindh and the AKU project areas, and this percentage was included in the surveys. However, the population living in camps in Punjab were excluded from the sample, due to very insignificant numbers.

Table 1 shows that the majority of the people lived in mud/brick made houses in all three surveys while the proportion of people living in 'thatch homes' was higher in Sindh (21 per cent in the north and 15 per cent in the south) compared to Punjab (1-3 per cent) but AKU project areas (38 per cent) had the highest proportion of thatched homes, probably because they were working close to IDP locations. In the case of toilet facilities, almost half (46-50 per cent) of the households in Sindh did not have any toilet facilities and defecating in open areas was rather higher in Punjab (56-60 per cent) but lower in AKU project areas (35 per cent). Interestingly, the proportion of households with soap available for handwashing (interviewers observed) was high in all the areas (67-72 per cent in Sindh, 67-80 per cent in Punjab and 86 per cent in AKU project areas). Of course the proportion of households with piped water as a source of drinking water was lowest in Sindh (4-8 per cent), highest in Punjab (11-21 per cent) and 13 per cent in AKU project areas.

Although the association of poverty and vulnerability to environmental disasters is well recognised (Brouwer et al. 2007), the usual gradients of undernutrition in relation to poverty and food insecurity may not be evident in uniformly poor populations (Singh et al. 2006). The findings that there was no notable gradient of nutrition indicators with asset quintiles or indicators for the given population may reflect the widespread nature of poverty and few differentials among asset holdings in the population. The classification of households on the basis of asset holdings may not be valid among displaced populations in emergency settings.

\subsection{Malnutrition status}

Prevalence of Global Acute Malnutrition (GAM) was highest in Sindh (21-23 per cent) compared 


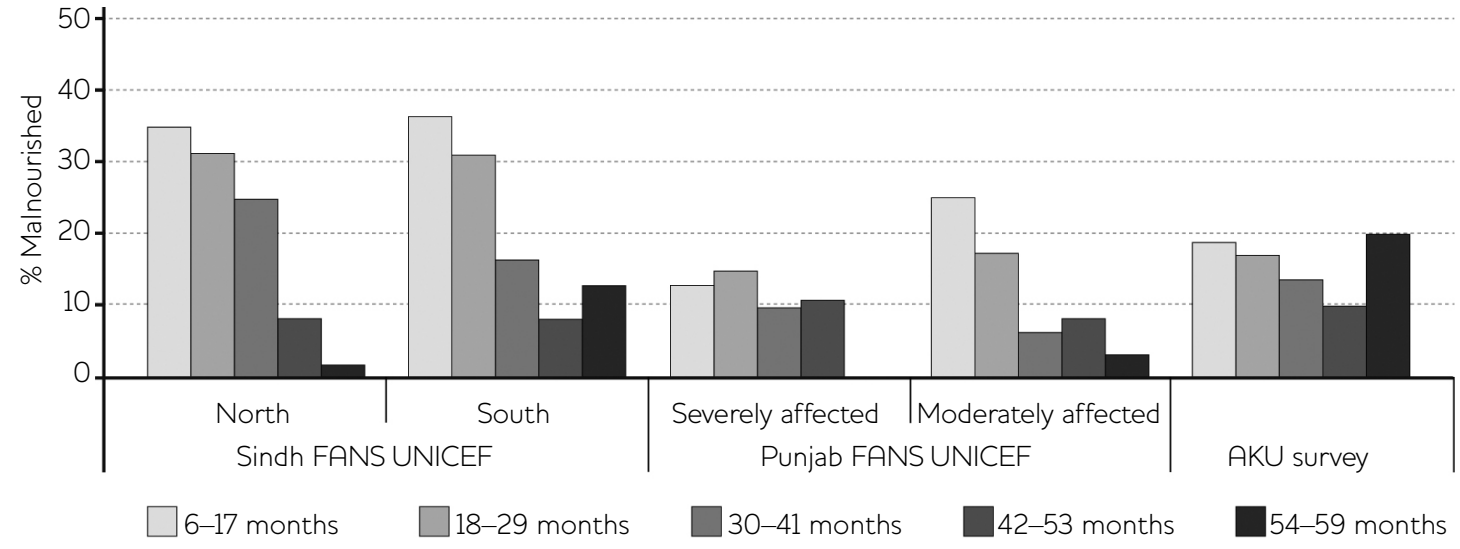

Source Authors' own.

Table 3 Prevalence of stunting among different groups in Sindh, Punjab and AKU project areas

\begin{tabular}{llll}
\multicolumn{2}{c}{ Sindh FANS UNICEF } & \multicolumn{2}{c}{ Punjab FANS UNICEF } \\
North Sindh & South Sindh & $\begin{array}{l}\text { Severely } \\
\text { affected }\end{array}$ & $\begin{array}{l}\text { Moderately } \\
\text { affected }\end{array}$
\end{tabular} AKU surveys

Age (months)

\begin{tabular}{|c|c|c|c|c|c|}
\hline 6-17 & $41(55.4)$ & $29(45.2)$ & 39 (42.2) & $56(50.9)$ & $108(54.5)$ \\
\hline $18-29$ & $65(63.7)$ & $51(60.7)$ & $65(56)$ & $73(60.4)$ & $147(79.4)$ \\
\hline $30-41$ & $50(52.6)$ & $57(58.2)$ & $57(41)$ & $81(53.3)$ & $107(72.2)$ \\
\hline $42-53$ & $42(52.5)$ & $35(43.8)$ & $51(46)$ & $67(49.6)$ & $47(51.1)$ \\
\hline $54-59$ & $15(34.1)$ & $13(42.0)$ & $12(41)$ & $11(39.3)$ & $4(36.4)$ \\
\hline Total & $213(53.8)$ & $185(51.8)$ & $224(46)$ & $288(52.8)$ & $413(65.2)$ \\
\hline \multicolumn{6}{|l|}{ Gender } \\
\hline Boys & 115 (55.3) & $88(48.1)$ & $130(55.3)$ & $152(53.3)$ & $201(62.2)$ \\
\hline Girls & $98(52.4)$ & $97(55.7)$ & $94(38.5)$ & $136(52.1)$ & $212(68.2)$ \\
\hline Total & 213 (53.9) & $185(51.8)$ & $224(46.8)$ & $288(52.7)$ & $413(65.1)$ \\
\hline \multicolumn{6}{|c|}{ Socioeconomic status } \\
\hline Quintile I & $70(51.1)$ & $103(54.2)$ & $21(47.7)$ & $47(51.6)$ & $71(60.2)$ \\
\hline Quintile II & $24(57.1)$ & $4(66.7)$ & $86(50.0)$ & $113(58.9)$ & $94(72.3)$ \\
\hline Quintile III & $47(58.8)$ & $27(50.9)$ & $43(52.4)$ & $62(61.4)$ & 89 (71.2) \\
\hline Quintile IV & $50(53.8)$ & $19(41.3)$ & $31(46.3)$ & $32(60.4)$ & $90(67.2)$ \\
\hline Quintile V & $20(42.6)$ & 30 (46.2) & 45 (38.1) & 37 (33.9) & $69(55.6)$ \\
\hline
\end{tabular}

Source Authors' own. 
Table 4 Feeding practices, child illness and supplementation coverage in Sindh, Punjab and AKU project areas

\begin{tabular}{|c|c|c|c|c|c|}
\hline & \multicolumn{2}{|c|}{ Sindh FANS UNICEF } & \multicolumn{2}{|c|}{ Punjab FANS UNICEF } & \multirow[b]{2}{*}{ AKU surveys } \\
\hline & North Sindh & South Sindh & $\begin{array}{l}\text { Severely } \\
\text { affected }\end{array}$ & $\begin{array}{l}\text { Moderately } \\
\text { affected }\end{array}$ & \\
\hline \multicolumn{6}{|l|}{ Initiation of breastfeeding } \\
\hline within 1 hour after birth & $124(80.5)$ & $101(81.5)$ & $45(23.2)$ & $41(25.5)$ & $70(48.6)$ \\
\hline$>1$ hour & $30(19.5)$ & $23(18.5)$ & $142(73.2)$ & $114(70.8)$ & $73(50.7)$ \\
\hline Never & - & - & $7(3.6)$ & $6(3.7)$ & $1(0.7)$ \\
\hline Total & 154 & 124 & 194 & 161 & 144 \\
\hline \multicolumn{6}{|c|}{ Are you still breastfeeding your child? } \\
\hline Yes & $47(42.7)$ & $48(49.5)$ & $141(75.8)$ & $115(71.4)$ & $141(96.6)$ \\
\hline No & $63(57.3)$ & $49(50.5)$ & $45(24.2)$ & $46(28.6)$ & $5(3.4)$ \\
\hline Total & 110 & 97 & 186 & 161 & 146 \\
\hline \multicolumn{6}{|c|}{ Child illness during the past 2 weeks } \\
\hline Yes & $248(54.6)$ & $168(42.6)$ & $438(72.5)$ & $321(61)$ & $630(66.7)$ \\
\hline No & $206(45.4)$ & $226(57.4)$ & $166(27.5)$ & 205 (39) & $315(33.3)$ \\
\hline $\mathrm{N}$ & 454 & 394 & 604 & 526 & 945 \\
\hline \multicolumn{6}{|l|}{ Diarrhoea in last 2 weeks } \\
\hline Yes & $62(25)$ & $33(19.6)$ & $90(20.5)$ & $40(12.5)$ & $325(34.6)$ \\
\hline No & $186(75)$ & $135(80.4)$ & $348(79.5)$ & $281(87.5)$ & $613(65.4)$ \\
\hline$N$ & 248 & 168 & 438 & 321 & 938 \\
\hline \multicolumn{6}{|l|}{ ARI in last 2 weeks } \\
\hline Yes & $73(29.4)$ & $36(21.4)$ & $49(11.2)$ & $40(12.5)$ & $315(33.4)$ \\
\hline No & $175(70.6)$ & $132(78.6)$ & $389(88.8)$ & $281(87.5)$ & $628(66.6)$ \\
\hline $\mathrm{N}$ & 248 & 168 & 438 & 321 & 943 \\
\hline \multicolumn{6}{|c|}{ Has the child received vitamin A supplementation? } \\
\hline Yes & $118(25.8)$ & $320(80)$ & $247(40.6)$ & $410(80.1)$ & 298 (32.2) \\
\hline No & $339(74.2)$ & $80(20)$ & $362(59.4)$ & 102 (19.9) & $602(65.1)$ \\
\hline Don't know & - & - & - & - & $25(2.7)$ \\
\hline $\mathrm{N}$ & 457 & 400 & 609 & 512 & 925 \\
\hline
\end{tabular}

Source Authors' own.

to Punjab (14 per cent) and AKU project areas (16 per cent). The prevalence of GAM did not vary between the north and south of Sindh or severely and moderately affected flooded areas in Punjab - indicating that probably the extent of flooding did not have much influence on the nutrition status (Table 2).

The most important revelation from these surveys was the prevalence of chronic malnutrition (stunting) which was again highest among the children in Sindh (52-54 per cent) compared to Punjab (46-53 per cent) and AKU project areas (48 per cent). Although this prevalence varied between different regions within the provinces the variations were not statistically significant. Obviously, stunting is an indicator of a long-term condition as opposed to acute malnutrition, and it is unlikely that stunting status would be affected within just three months of the flooding. The lack of variations between different regions indicates that stunting is widespread throughout the poor population of Pakistan, independent of the 2010 floods.

However, when the GAM children were analysed more discretely by age group (Figure 1), it is obvious that the prevalence was higher in the younger age group (less than 30 months) compared to the older age group (over 30 months) in Sindh and Punjab but not in AKU project areas, and not in the moderately affected flooded areas of Punjab where all age groups seem to be equally affected by malnutrition. In Sindh, the prevalence of GAM was more than 
Table 5 Micronutrient status of children under five in AKU project areas

\begin{tabular}{ll}
\hline Indicators & n (\%) \\
\hline Vitamin A $(\boldsymbol{\mu g m} / \mathrm{dL})$ & \\
$\quad$ Deficient to low $(<=20)$ & $286(55.3)$ \\
Marginal to adequate $(>20)$ & $231(44.7)$ \\
Total & 517 \\
\hline Vitamin D (ng/ml) & \\
Severe deficiency $(<8 \mathrm{ng} / \mathrm{mL})$ & $49(10)$ \\
Deficiency $(8-20 \mathrm{ng} / \mathrm{mL})$ & $284(58.2)$ \\
Insufficiency $(21-29 \mathrm{ng} / \mathrm{mL})$ & $125(25.6)$ \\
Sufficiency $(>30 \mathrm{ng} / \mathrm{mL})$ & $30(6.1)$ \\
Total & 488 \\
\hline Hgb (g/dL) & \\
Normal $(\geq 11)$ & $119(22.2)$ \\
Mild $(10-10.9)$ & $110(20.5)$ \\
Moderate $(7.0-9.9)$ & $293(54.6)$ \\
Severe $(<7.0)$ & $15(2.8)$ \\
\hline Anaemic $(<11)$ & $418(77.8)$ \\
\hline Total & 537
\end{tabular}

Source Authors' own.

30 per cent in the younger age groups, compared to around 10 per cent in the older age group, while in Punjab it was different; the same trend was observed in severely affected areas (20 per cent vs. 10 per cent) but not in moderately floodaffected areas.

Further investigation into stunting revealed that stunting was also higher among the younger age groups (42-64 per cent in Sindh and Punjab and 55-80 per cent in AKU project areas) compared to older age groups (around 35-53 per cent in Sindh, 40-50 per cent in Punjab and 35-50 per cent in AKU project areas). When divided between boys and girls, girls seem to suffer more in southern Sindh (56 vs. 48 per cent) and AKU project areas (68 vs. 62 per cent) while boys seem to suffer more in the severely flood-affected areas of Punjab (55 vs. 39 per cent) (see Table 3).

\subsection{Feeding practices, morbidity and supplementation coverage}

It was interesting to observe that while about 80 per cent of children in Sindh initiated breastfeeding within one hour of birth, it was only 23-26 per cent in Punjab and 49 per cent in AKU project areas. However, paradoxically, the rate of continuation of breastfeeding (as on the day of survey) was highest among children in AKU project areas (97 per cent) followed by Punjab (71-76 per cent) and Sindh (43-50 per cent) (see Table 4).

Morbidity was highest in the severely floodaffected areas of Punjab (73 per cent) compared to Sindh (43-55 per cent). In Sindh, 20-25 per cent of the children were suffering from diarrhoea, which was 13-21 per cent in Punjab, but 35 per cent in AKU project areas. About 33 per cent of children in AKU project areas suffered from Acute Respiratory Infection (ARI), which was 21-29 per cent in Sindh and 11-13 per cent in Punjab.

Only 26 per cent of children in northern Sindh and 32 per cent in AKU project areas received vitamin A supplementation within six months prior to the date of the survey; this was 80 per cent in southern Sindh and the moderately flood-affected areas of Punjab. The morbidity and vitamin A data confirm that of the five surveys, children in the AKU project areas are most at risk.

\subsection{Micronutrient status}

Biological samples were drawn only from AKU project areas. Around 55 per cent of children under five years were found to be vitamin A deficient, while 58 per cent were suffering from vitamin $\mathrm{D}$ deficiency, and with around 10 per cent having severe deficiency. Only 22 per cent among these children had normal haemoglobin $(>11 \mathrm{~g} / \mathrm{dL})$ and the rest (78 per cent) were anaemic; this included 57 per cent moderate to severe $\mathrm{Hb}$ deficiency (see Table 5).

\section{Discussion}

\subsection{Nutrition epidemiology}

The 2010 large-scale disaster negatively impacted on progress towards achievement of the Millennium Development Goals for Pakistan as malnutrition has often been a major contributing factor to high death rates among refugees and internally displaced persons (IDPs). A study of children of IDPs aged 6-59 months from northern Chad reported a very high figure of 20.6 per cent (95 per cent CI, 17.9-23.3 per cent) prevalence of acute malnutrition rates (according to WHO standards), compared to 16.4 per cent (95 per cent CI, 14.0-18.8 per cent) in children of non-displaced persons (NDPs) living in villages, and 10.1 per cent (95 per cent CI, 8.1-12.2 per cent) in towns (Guerrier et al. 2009). A 45 per 
cent prevalence rate of acute malnutrition was reported in children younger than five years of age among Sudanese refugees arriving in Ethiopia during 1990, 29 per cent among Somali refugees in Kenya in 1991, and 48 per cent among Mozambican refugees arriving in Zimbabwe in 1992 (Toole and Waldman 1993).

In a Pakistan earthquake 2005 survey (Hossain 2006), GAM was reported as 10.5 per cent (95 per cent CI, 6.7-14.3 per cent), while stunting was 38.1 per cent in Muzaffarabad and 54.8 per cent in NWFP (former name of Khyber Pakhtunkhwa province); 50 per cent of nursing mothers had reduced breastfeeding and around 15 per cent had stopped breastfeeding since the earthquake happened. In the IDP camps of Sri Lanka during the 2009 war, GAM was observed to be 36 per cent (one of the highest in the world) but was brought down to around 14 per cent (Jayatissa and Hossain 2009) in nine months (March-December 2009) through a very systematic implementation of the CommunityBased Management of Acute Malnutrition (CMAM) programme in the IDP camps. However, these figures underscore the sudden huge burden of poor nutritional status that arises after such humanitarian crises.

\subsection{Lessons learnt from methodological issues}

Assessments conducted in times of crisis have limitations and problems due to lack of ready information, time constraints, and harsh working conditions, and these have been documented previously (Richardson et al. 2006). The surveys in Pakistan are no exception, in terms of the issues of representativeness, available human resources for maintaining high standards in data collection, selecting clusters and households within clusters and calculation of sample size and sampling unit. One of the major challenges was whether or not to include IDP camps and villages in the same survey or not. Some of the problems encountered, mistakes made, and solutions found are just as valuable as the results and are described at length in the respective survey reports (DoH/UNICEF/ACF 2011; and Rafique et al. 2011).

\subsection{Increased awareness, immediate response and wake-up call for long-term strategy}

The results of both FANS were officially launched by the respective provincial authorities with highlevel media coverage and a political commitment that led to an immediate response plan worth around US $\$ 80$ million for the two provinces. Task forces were formed in both provinces under the leadership of the Department of Health with participation from a wide range of stakeholders to develop a short and long-term nutrition response plan along with a budget prepared for the donors. Though not totally funded by the donors, a large-scale CMAM programme was launched in both the provinces. The AKU survey also generated a positive response from the donors to support their project areas.

\section{However, the Pakistan 2010 flood clearly} revealed what has always existed and there was no evidence that the floods had induced acute malnutrition among these women and children, since there was no baseline data in the floodaffected areas. Hence, there was no awareness that both acute and chronic malnutrition is an endemic problem in Pakistan. However, the findings of the FANS helped raise the awareness of malnutrition among the political leadership, policymakers and senior managers which led to a large-scale immediate response and a long-term strategy.

As the FANS in Sindh was implemented by the Department of Health and in Punjab by the Punjab Bureau of Statistics, it was felt that there was a huge need to improve the quality of the health care providers and data collection team regarding the anthropometric measurement; this was implemented with subsequent training.

The FANS results were substantially backed up by the preliminary findings of the National Nutrition Survey 2001 which found similar figures for GAM and Severe Acute Malnutrition (SAM). This led to a high-level focus on nutrition as a priority at federal and provincial levels and the development of the Pakistan Integrated Nutrition Strategy (PINS) at federal level and policy briefs for provinces. The PINS focuses on inter-sectoral intervention and coordination for tackling malnutrition in Pakistan, to address the underlying and intermediate causes of the problem rather than limiting interventions to health responses. Based on PINS, provincial governments are aiming for integration of nutrition intervention in relevant ministries and to allocate budget from the standard government financing mechanism of the Planning Commission (PC1). 


\section{Notes}

* S.M. Moazzem Hossain was working in Pakistan during Flood Response 2010 as part of UNICEF Pakistan as a secondee from UNICEF Sri Lanka; Mah Talat was a staff member of UNICEF Lahore at the time of survey and was deployed to Multan.

** The authors would like to express thanks to UNICEF for funding the FANS and USAID for funding the AKU survey. Technical support from CDC and ACF during the FANS data

\section{References}

Brouwer, R.; Akter, S.; Brander, L. and Haque, E. (2007) 'Socioeconomic Vulnerability and Adaptation to Environmental Risk: A Case Study of Climate Change and Flooding in Bangladesh', Risk Anal. 27.2: 313-26

DoH/UNICEF/ACF (2011) Flood Affected Nutrition Surveys in Sindh, Department of Health, Government of Sindh in collaboration with UNICEF and ACF

Guerrier, G.; Zounoun, M. and Delarosa O. et al. (2009) 'Malnutrition and Mortality Patterns among Internally Displaced and NonDisplaced Population Living in a Camp, a Village or a Town in Eastern Chad', PLOS One 4.11: e8077

Hossain, S.M.M. (2006) Health and Nutrition Survey in Earthquake Affected Areas of Pakistan, Islamabad UNICEF/WFP/WHO joint survey in collaboration with Ministry of Health, Government of Pakistan, 7 February Jayatissa, R. and Hossain, S.M.M. (2009) Rapid Nutrition Assessment in IDP Camps, Medical Research Institute and UNICEF Sri Lanka collection is also appreciated. The special efforts of Mr Shafat Sharif and his team of Eycon (Pvt) Ltd for cleaning the dataset for this analysis deserve appreciation. We are grateful to Karen Allen, Deputy Representative of UNICEF Pakistan for reviewing this article.

\section{Disclaimer}

The opinions expressed in this article are those of the authors and not of UNICEF or Save the Children.

Rafique, S.; Hossain, S.M.M.; Aurore, B. et al. (2011) Nutrition Survey in Flood Affected Areas of Punjab Province, Bureau of Statistics, Planning and Development Department, Government of The Punjab in collaboration with UNICEF and $\mathrm{ACF}$

Richardson, L.; Hossain, S.M.M. and Sullivan, K. (2006) 'The Pakistan Earthquake Survey Methodological Lessons Learnt', Field Exchange 28, Emergency Nutrition Network: 26-30

Singh, M.B.; Fotedar, R.; Lakshminarayana, J. et al. (2006) 'Studies on the Nutritional Status of Children Aged 0-5 Years in a Droughtaffected Desert Area of Western Rajasthan, India', Public Health Nutr. 9.8: 961-7

Toole, M.J. and Waldman, R.J. (1993) 'Refugees and Displaced Persons: War, Hunger, and Public Health', JAMA 270: 600-05

UNOCHA (2010) Pakistan Monsoon Floods, Situation Reports 27, United Nations Office for the Coordination of Humanitarian Affairs in Pakistan 